\title{
Disability and health service utilization among old Koreans
}

\author{
Ju Moon Park \\ Incheon National University, Incheon, South Korea; jumoonpark@incheon.ac.kr
}

Received 9 December 2013; revised 9 January 2014; accepted 17 January 2014

Copyright (C 2014 Ju Moon Park. This is an open access article distributed under the Creative Commons Attribution License, which permits unrestricted use, distribution, and reproduction in any medium, provided the original work is properly cited. In accordance of the Creative Commons Attribution License all Copyrights @ 2014 are reserved for SCIRP and the owner of the intellectual property Ju Moon Park. All Copyright (C) 2014 are guarded by law and by SCIRP as a guardian.

\section{ABSTRACT}

This study compared persons with disabilities with those without disabilities in terms of health services utilization and examined the factors associated with the use of inpatient hospital services. Data on a sample of $\mathbf{4 0 4 0}$ older adults (65+ years of age) from the Korean Longitudinal Study of Ageing were used. Descriptive and logistic regression analysis was performed examining sample characteristics of participants with and without disabilities and factors significantly associated with health services utilization. This study showed that the elderly with disabilities used significantly more inpatient hospital services than the elderly without disabilities. As expected, poor health was clearly the most influential factor explaining the use of inpatient hospital services. The second most influential factor in determining use of medical services is disability. Persons with disabilities had a twofold or more increase in the odds of using inpatient hospital services. Likewise, the person with chronic condition had also an additional twofold increase in risk for medical services due to the chronic condition. Chronic conditions were clearly the third influential factor explaining the use of inpatient hospital services. Finally, females were a small margin more likely to use inpatient hospital services than males.

\section{KEYWORDS}

Disability; Health Status; Chronic Condition; Hospitalization; Older Koreans

\section{INTRODUCTION}

In the Republic of Korea (hereafter Korea), the entry of baby-boomers born between 1955 and 1965 into old age is a social policy issue. It is because Korean society is aging faster than any other country as the "baby boomers" grow older. Korea has entered into becoming an aging society with over $7 \%$ of the entire population aged over 65 in year 2000. The speed of aging in Korea is unprecedented in human history [1], 18 years to double aging population from $7 \%$ - $14 \%$ (least number of years) [2], overtaking even Japan. The percentage of the elderly aged 65 and above has increased from $7.2 \%$ in 2000 to $11.3 \%$ in 2010 , but it is expected to rise to $14.0 \%$ by 2017 and $37.4 \%$ in 2050 [3].

Despite the fact that disability is increased with the aging of the entire population, there has been a paucity of reliable and representative data on disability issues of Koreans $[4,5]$. The analyses reported here are based on cross-sectional data from the 2008 Korean Longitudinal Study of Aging. Since timely healthcare is somewhat limited in access, the disease becomes aggravated and people with disabilities have unnecessary hospitalization [6]. In addition, the prevalence of chronic disease is 2 to 3 times higher in patients with disabilities than in those without. Therefore, secondary functional losses such as heart disease or stroke can be added to their primary disabilities [7]. Also, people with disabilities meet their healthcare needs less than those without disabilities [8]. In particular, although the introduction of the national medical insurance policy gradually improves their access to medical facilities, the medical insurance policy in Korea has been criticized due to financial burdens and the imbalance of the medical infrastructure [9]. Thus, it is necessary to compare persons with disabilities with those without disabilities in term of health services utilization from the consumers' point of view.

Previous work addressing disability and the use of health services has generally been limited. Research [10-14] has shown that health and disability-related need factors were important determinants of Koreans using 
health care services and socio-economic factors rather than health and disability-related factors had less predictive power of the use of health services. It is important to consider the disability of the population because of their health problem and susceptibility to chronic conditions. I aim to use national statistics on disability and health to address the following two objectives:

1) To compare persons with disabilities with their counterparts in terms of health services utilization;

2) To show the factors associated with the use of inpatient hospital services.

\section{METHODS}

\subsection{Sample}

The present study focuses on cross-sectional analyses, using the 2008 Korean Longitudinal Study of Ageing which was conducted with Korean men and women aged 45 years or older. From the total sample 6,437, individuals less than 54 years of age were eliminated from this analysis, leaving a sample more than 55 years of age. 476 participants were excluded from the sample because they were missing disability-specific information, and thus could not be classified as disabled or nondisabled. Thus, the sample for this study was 5,961 individuals who indicated 55 years old or older. The survey design was a 2-stage stratified cluster sampling framed by the national population and housing census.

For the analysis, the sample was weighted to reflect the population of the nation. To account for design effects created by stratified multistage cluster sampling, weights and strata were used in estimation.

\subsection{Measures}

Demographic and socioeconomic measures include age, gender, marital status, education, and income. The health measures of health status included questions on whether the subject considered his or her health to be very good, good, fair, poor or very poor, and whether a chronic condition had been a problem during the last 24 months. Health services utilization include hospitalization. For hospitalization, the respondents were asked whether they had been a patient in a hospital during the 24 months preceding the interview.

For the logistic regression analyses, the study variables were recoded to indicate dichotomies. The first category for a variable was coded 1 and the reference category for it (after "vs") was coded 0. Health status, which is one of need factors, is not a well-defined concept, but it is widely used. The several measures of health status are all reported in an interview format, and range from the highly subjective (e.g. self-evaluation) to the more objective (e.g. conditions checked by a nursing assistant) [9]. In this study, three measures of health status were respectively represented as a dichotomy, i.e. "fairt" (1) versus "poor" (0), "one or more chronic condition" (1) versus "no condition" (0), and "having a disability" (1) versus "not having a disability" (0). In addition to health status of the elderly, utilization of health care services is closely related to demographic factorsin particular age and sex. As proxies for need, age and sex were respectively represented as a dichotomy, i.e., “75+" (1) versus “55 - 74” (0) and "male” (1) versus "female" (0) in this analysis. Marital status was used in this analysis and was represented by the binary variable "unmarried or divorced or widowed" (1) versus "married" (0). A categorical factor indicating the level of education attained is used as a supplementary measure of socioeconomic status. In this study, education was represented by the binary factor "middle school graduate +" (1) versus "primary school graduate" (0). As personal resources relate to service use, income was included. In the present study, income refers to totals for individual. The total annual income before deductions were reported, “ $\leq 10,000,000$ won (USD8800) to " $>10,000,000$ won". Income was represented by the dichotomous factor “ $\leq 10,000,000$ won” ( 1 ) versus “ $>10,000,000$ won” ( 0 ).

\subsection{Data Analysis}

Descriptive statistics such as mean, standard deviation (SD), frequency and percentage were used to analyze the demographic and socio-economic characteristics of the sample. Bivariate analyses (chi-square tests) were used to examine sample characteristics of participants with and without disabilities. Logistic regression analyses were then used to determine factors significantly associated with health services utilization. To assess the effects of health, disability, and socioeconomic factors on health services utilization, the analyses were conducted in a series of stages. Only the health variable was entered in stage 1 , since health is believed to be the most deterministic factor in health service utilization. In stage 2, disability-related variables, which are variables of interest, were entered. In this way, the model permits us to show the additional variance explained by disability, even after the effects of health have been accounted for. At the final stage, the socioeconomic variables were entered in order to identify the improvement in model fit that can be achieved by also accounting for personal factors like age, gender, socioeconomic status. Dependent variable in the logistic regression models included hospitalization. Independent variables were age, gender, education, marital status, income and health and disability-related variables. To avoid over-fitting the model, only variables found significant on univariate analysis were included in the final regression model. All tests were conducted at the $5 \%$ level of significance. The percentage and the odds 
ratio (OR) were reported with their 95\% Confidence interval (CI).

\section{RESULTS}

\subsection{Demographic and Other Characteristics}

Survey respondents had higher percentage with no formal education or primary education, higher percentage with income of 2.5 million won (USD $=2,200$ ) or less and higher percentage who were younger, female, and married (Table 1). The average age of the respondents was $68.3 \pm 8.7$ years old, $37.5 \%$ aged $55-64$ years, $38.7 \%$ aged $65-74$ years, and $23.8 \%$ aged above 75 . $57.7 \%$ of the respondents were female. $57.0 \%$ of the respondents had no formal or primary education, $16.6 \%$ had secondary education and $26.4 \%$ had tertiary education.73.1\% of the respondents were married. $44.1 \%$ of the respondents earned total annual income of $\leq 2.5$ million won, 28.8\% earned 2.5 - 10 million won, and 27.1\% earned $>10$ million won. The annual average income respondents earned was $8,993,886.9( \pm 1301.1)$ won. $26.7 \%$ of the respondents rated their health "good" or "very good", 39.5\% rated their health "fair" and 33.8\% rated their health "poor" or "very poor". The prevalence of self-reported chronic diseases was $20.6 \%$. The prevalence of a disability was $4.5 \%$. As for hospital admission,
$13.5 \%$ of the respondents had been admitted at least once during the past 24 months. The mean number of hospitalization was $0.2( \pm 0.6)$.

\subsection{Bivariate Analysis}

Table 1 compares the members of the sample that are disabled and nondisabled in terms of demographic and socioeconomic factors. It shows that the members of the sample that were disabled were significantly poorer, and less well-educated than those in the sample that were nondisabled. They were less likely to be divorced, widowed, or single and more likely to be married. Table 2 also shows the distribution of health and disability-related variables in the sample. As expected, the sample of members with disabilities had a significantly greater prevalence of chronic conditions. The sample of members who were disabled was also significantly more likely to report health in the fair to very poor range (75.5\%), whereas the sample of those without disabilities tended to report good to very good health (24.5\%).

\subsection{Multivariate Analysis}

The first objective of the study was to compare respondents with and without disabilities in terms of the utilization of health services (Table 2). With regard to

Table 1. Demographic and socioeconomic characteristics of the sample $(\mathrm{N}=5961)$.

\begin{tabular}{|c|c|c|c|}
\hline Characteristics & Categories & $\mathrm{N}(\%)$ & $\operatorname{Mean}( \pm \mathrm{SD})$ \\
\hline Age & $55-64$ & $2,397(37.5)$ & $68.3( \pm 8.7)$ \\
\hline \multirow[t]{2}{*}{ (years) } & $65-74$ & $2,505(38.7)$ & \\
\hline & $75+$ & $1,535(23.8)$ & \\
\hline \multirow[t]{2}{*}{ Sex } & Male & 2,801(42.3) & \\
\hline & Female & $3,636(57.7)$ & \\
\hline Marital status & Others & $1,706(26.9)$ & \\
\hline Education & Primary school & $3,687(57.0)$ & \\
\hline \multirow[t]{2}{*}{ (graduation) } & Middle school & $1,058(16.6)$ & \\
\hline & High school & $+1,692(26.4)$ & \\
\hline \multirow[t]{3}{*}{ Income $^{\#}$} & $\leq 2,500,000$ won & $2,840(44.1)$ & $8,993,886.983( \pm 1301.1)$ \\
\hline & $2,510,000-10,000,000$ won & 1,896(28.8) & \\
\hline & $>10,000,00$ won & $1,701(27.1)$ & \\
\hline \multirow{2}{*}{ Health status } & Fair & $2,456(39.5)$ & \\
\hline & Poor & 2,317(39.8) & \\
\hline Chronic & No & $5,099(79.4)$ & \\
\hline Conditions $^{*}$ & Yes & $1,338(20.6)$ & \\
\hline \multirow[t]{2}{*}{ Disability } & No & $6,056(95.5)$ & \\
\hline & Yes & $381(4.5)$ & \\
\hline Health services & Hospitalization & & \\
\hline \multirow[t]{3}{*}{ Utilization } & 0 & $5,154(86.5)$ & $0.2( \pm 0.6)$ \\
\hline & 1 & 731(10.9) & \\
\hline & $2+$ & $192(2.6)$ & \\
\hline
\end{tabular}

*Refers to hypertension, arthritis, diabetes, lung problems, prostate, mental problems, heart disease, cancer, liver problems, uracratia and stroke. ${ }^{\#}$ Income in Korean monetary unit. 
Table 2. Sample characteristics of participants with and without disabilities, weighted.

\begin{tabular}{|c|c|c|c|c|}
\hline Characteristics & Categories & Disabled & Non-disabled & p-value \\
\hline Age & $55-64$ & 33.0 & 37.6 & \\
\hline \multirow[t]{2}{*}{ (years) } & $65-74$ & 39.4 & 38.7 & \\
\hline & $75+$ & 27.6 & 23.7 & \\
\hline \multirow[t]{2}{*}{ Sex } & Male & 50.0 & 57.9 & \\
\hline & Female & 50.0 & 42.1 & \\
\hline \multirow[t]{2}{*}{ Marital status } & Others & 18.1 & 27.0 & $<0.05$ \\
\hline & Married & 81.9 & 73.0 & \\
\hline Education & Primary school & 59.6 & 56.9 & $<0.01$ \\
\hline \multirow[t]{2}{*}{ (graduation) } & Middle school & 25.5 & 16.5 & \\
\hline & High school+ & 14.9 & 26.6 & \\
\hline \multirow[t]{3}{*}{ Income $^{\#}$} & $\leq 2,500,000$ won & 48.9 & 44.0 & $<0.01$ \\
\hline & $2,510,000$ - 10,000,000 won & 41.5 & 26.6 & \\
\hline & $>10,000,00$ won & 9.6 & 27.4 & \\
\hline \multirow[t]{3}{*}{ Health status } & Good + & 6.4 & 27.1 & $<0.01$ \\
\hline & Fair & 18.1 & 39.8 & \\
\hline & Poor & 75.5 & 33.1 & \\
\hline Chronic & No & 61.7 & 79.7 & $<0.01$ \\
\hline Conditions & Yes & 38.3 & 20.3 & \\
\hline \multicolumn{5}{|l|}{ Health services } \\
\hline utilization rate & Hospitalization & 36.2 & 13.2 & $<0.01$ \\
\hline
\end{tabular}

* Refers to hypertension, arthritis, diabetes, lung problems, prostate, mental problems, heart disease, cancer, liver problems, uracratia and stroke. \#Income in Korean monetary unit.2.5 million won accounts for about US\$2200. Note: All other statistics not significant at $\mathrm{p}<0.05$.

inpatient hospital services, the elderly with disabilities used significantly more of inpatient hospital services than the elderly without disabilities. Persons with disabilities were about three times more likely to have received inpatient hospital services during the past 24 months.

To determine the factors that affect utilization of health services (Objective II), a separate multivariate model was constructed for inpatient hospital services utilization variable of interest. Table 3 shows the factors affecting the use of health services according to respondents. As expected, poor health was clearly the most influential factor explaining the use of inpatient hospital services. Poor health results in more than a threefold increase in the odds of using inpatient hospital services. The second most influential factor in determining use of medical services is disability. Persons with disabilities had a twofold or more increase in the odds of using inpatient hospital services. It should be emphasized that this increase in risk was over and above that attributed to poor health, since health was already in the model. In other words, for two persons, one disabled and one nondisabled, both of whom estimated their health as poor, the person with disabilities had an additional twofold increase in risk for medical services due to the disability. Likewise, the person with chronic condition had also an additional twofold increase in risk for medical services due to the chronic condition. With regard to the particular problems that brought people to see a specialist, chronic conditions were clearly the third influential factor explaining the use of inpatient hospital services.
Finally, socioeconomic variables were entered in stage 3 to see if significant additional variance could be explained as a function of those. In inpatient hospital care, about a one-fold increase in utilization was observed for female over male. Females were a small margin more likely to use inpatient hospital services than males.

All regression models were significant $(p<0.0001)$ in predicting old Korans of inpatient hospital services.

\section{DISCUSSION}

This study shows that persons with disabilities are high users of inpatient hospital services. This finding substantiates Korean findings cited earlier [13,14]. However, this study adds an important dimension to the existing literature: that is, disability is clearly associated with a threefold increase in the risk of using inpatient hospital services. In other words, over and above the utilization predicted by health status, there is an additional margin of risk explained by disability. Given two individuals of equal health status, the person with disabilities are more than two times likely to still have used inpatient hospital services than their counterparts. Chronic condition is also associated with a twofold increase in the risk of using inpatient hospital services. Finally, with regard to demographic variables, sex has significant effect on the utilization of inpatient hospital services. It is however noteworthy that there was no association between income and use of inpatient hospital services. In Korea, inpatient hospital services tend to be covered by the national health insurance system [15]. They tend not to be avail 
Table 3. Multivariate logistic regression analysis of predictors of hospitalization for old Koreans, weighted.

\begin{tabular}{|c|c|c|c|c|c|c|}
\hline \multirow{3}{*}{ Determinants } & \multicolumn{6}{|c|}{ Inpatient hospital services utilization } \\
\hline & \multicolumn{2}{|c|}{ Stage I } & \multicolumn{2}{|c|}{ Stage II } & \multicolumn{2}{|c|}{ Stage III } \\
\hline & OR & $95 \% \mathrm{CI}$ & OR & $95 \% \mathrm{CI}$ & OR & $95 \% \mathrm{CI}$ \\
\hline $\begin{array}{l}\text { Self-reported health status } \\
\text { Fair+ } \\
\text { vs. Poor }\end{array}$ & $3.93^{* *}$ & $3.27-4.71$ & $3.56^{* *}$ & $2.92-4.33$ & $3.79^{* *}$ & $3.08-4.67$ \\
\hline $\begin{array}{l}\text { Disability } \\
\text { One or more } \\
\text { vs. None }\end{array}$ & & & $2.18^{* *}$ & $1.28-3.71$ & $2.14^{* *}$ & $1.24-3.69$ \\
\hline $\begin{array}{l}\text { Chronic conditions } \\
\text { One or more } \\
\text { vs. None }\end{array}$ & & & $1.90^{* *}$ & $1.57-2.30$ & $1.94^{* *}$ & $1.59-2.36$ \\
\hline $\begin{array}{l}\text { Age } \\
75^{+} \\
\text {vs. } 55-74\end{array}$ & & & & & 0.92 & $0.74-1.14$ \\
\hline $\begin{array}{l}\text { Sex } \\
\text { Male } \\
\text { vs. Female }\end{array}$ & & & & & $0.78^{*}$ & $0.62-0.97$ \\
\hline $\begin{array}{l}\text { Marital status } \\
\text { Others } \\
\text { vs. Married }\end{array}$ & & & & & 1.06 & $0.86-1.32$ \\
\hline $\begin{array}{l}\text { Education } \\
\text { Middle school } \\
\text { vs. }+\leq \text { Primary school }\end{array}$ & & & & & 0.94 & $0.76-1.16$ \\
\hline $\begin{array}{l}\text { Income } \\
\leq 10,0000,000 \text { won } \\
\text { vs. }>10,000,000 \text { won }\end{array}$ & & & & & 0.88 & $0.68-1.13$ \\
\hline $\begin{array}{l}\text { Modelchi-square } \\
\text { Degree of freedom } \\
\text { Significance }\end{array}$ & & & & & & \\
\hline
\end{tabular}

${ }^{*} \mathrm{p}<0.05 .{ }^{* *} \mathrm{p}<0.01$. Note: $\mathrm{OR}=$ odds ratio; $\mathrm{CI}=$ confidence interval; All other statistics not significant at $\mathrm{p}<0.05$.

able on a private payment basis. Nevertheless, access to inpatient hospital services is still income-sensitive. This is particularly an issue in the population of persons with disabilities, which in this study and others, is overrepresented in the lower-income categories (see Table 2).

There are several limitations to this study. First, the model was limited to the data collected by Korean Labor Institute in 2008. Thus, the study did not fully operationalize the array of variables in the model. Second, the data relies on subjective measures of health status and does not include objective measures of chronic diseases. Third, the long (two-year) recall period used to ask about health services utilization can increase the amount of bias associated with respondent memory loss. Although the US National Center for Health Statistics National Health Interview Survey (NCHS-NHIS) uses a two-week recall period, that study is continuously in the field throughout the year, and data are used to construct aggregate estimates of volume of visits for the US population [16]. On the other hand, the Korean KLoSA uses a two-year recall period and data are used to construct volume of visits estimates for individuals. Therefore, seasonal bias and random errors are more likely to be problematic with the latter approach.

\section{CONCLUSIONS}

The findings of this study contain specific messages for several groups of stakeholders. The study findings provide information for policymakers about a group of health care system users who exert considerable pressure on the system, and whose needs are being inadequately met by the system. Second, for persons with disabilities, these data provide information about them as consumers of health services and offer the basis for targeted advocacy for improvements to access and quality of health services. Finally, $36.2 \%$ of persons with disabilities and $13.2 \%$ of persons without disabilities see a medical specialist in a given period. This finding highlights the importance of population-level consideration of persons with disabilities as consumers of health services. This level of information provides compelling data to policymakers, planners, and other decision makers to ensure 
that the issues of persons with disabilities are on the agenda for health reform and renewal.

\section{ACKNOWLEDGEMENTS}

This work was supported by the Incheon National University Research Grant in 2013. A special word of thanks goes to Korea Labor Institute which provided the data for this study.

\section{REFERENCES}

[1] Thomas, K. (2011) South Korean: Ageing Tiger. Global Brief 2010.

[2] Neil, H., Richard, J. and Keisuke, N. (2007) The aging of Korea: Demographics and retirement policy in the land of the morning calm. Center for Strategic and International Studies.

[3] Korean National Statistical Office (2012) Population statistics. Korean National Statistical Office, Daejeon.

[4] Korean Institute for Health and Social Affairs (2011) Survey on Actual Conditions of the Disabled. Ministry of Health and Social Affairs, Seoul.

[5] Ministry of Labor (2008) Report on Korean Longitudinal Study of Aging. Ministry of Labor, Seoul.

[6] Eun, S.J., Hong, J.Y., Lee, J.Y., Lee, J.S., Kim, Y., Kim, Y.I. and Shin, Y.S. (2006) Differences in medical care utilization rates of the disabled and the non-disabled with ambulatory care sensitive conditions. Journal of Preventive Medicine and Public Health, 39, 411-418.

[7] Clancy, C.M. and Andresen, E.M. (2002) Meeting the health care needs of persons with disabilities. Milbank Quarterly, 80, 381-391. http://dx.doi.org/10.1111/1468-0009.t01-1-00008

[8] Hwang, B.K., Chun, S.M., Park, J.H. and Shin, H.I. (2011)
Unmet healthcare needs in people with disabilities: Comparison with the general population in Korea. Annals of Physical and Rehabilitation Medicine, 35, 627-635.

[9] Park, K.S., Chun, B.Y., Kim, S., Yeh, M.H., Kang, Y.S., Kim, K.Y., Son, J.H. and Lee, Y.S. (1999) Structural relationships among health concern, health practice and health status of the disabled. Korean Journal of Preventive Medicine, 32, 276-288.

[10] Park, J.M. (1994) The determinants of physician and pharmacist utilization and equity of access under Korean universal health insurance. Ph.D. Dissertation, University of Texas, Houston.

[11] Park, J.M. (2012) Equity of access under Korean universal health insurance. Asia-Pacific Journal of Public Health.

[12] Jeon, B.Y., Kwon, S.M., Lee, H.J. and Kim, H.S. (2011) Factors associated with health services utilization among the disabled elderly in Korea. Korean Gerontology Review, 31, 171-188.

[13] Oh, J.S. (2005) Factors influencing on health services utilization among chronic patients with disabilities. Thesis, Yeonsei University, Seoul.

[14] Lee, S.Y. (2001) Equity of health services utilization among persons with disabilities: based on the self-employed under the national health insurance. Ph.D. Dissertation, Yeonsei University, Seoul.

[15] Park, J.M. (2011) Equity of access to primary care among older adults in Incheon, South Korea. Asia-Pacific Journal of Public Health.

[16] National Center for Health Statistics (1989) Vital and health statistics: Current estimates from the national health interview survey 1988. Series 10, No. 173. National Center for Health Statistics, Hyattsville. 